\title{
Modulation of Cytokine Production by Drugs with Antiepileptic or Mood Stabilizer Properties in Anti-CD3- and Anti-CD40-Stimulated Blood In Vitro
}

\author{
Hubertus Himmerich, ${ }^{1}$ Stefanie Bartsch, ${ }^{1}$ Hajo Hamer, ${ }^{2}$ Roland Mergl, ${ }^{1}$ \\ Jeremias Schönherr, ${ }^{1}$ Charlotte Petersein, ${ }^{1}$ Alexander Munzer, ${ }^{1}$ Kenneth Clifford Kirkby, ${ }^{3}$ \\ Katrin Bauer, ${ }^{4}$ and Ulrich Sack ${ }^{4}$ \\ ${ }^{1}$ Department of Psychiatry, University of Leipzig, Semmelweisstr. 10, 04103 Leipzig, Germany \\ ${ }^{2}$ Epilepsy Center, Department of Neurology, University Hospital Erlangen, 91054 Erlangen, Germany \\ ${ }^{3}$ Department of Psychiatry, University of Tasmania, Hobart, TAS 7001, Australia \\ ${ }^{4}$ Institute of Immunology, University of Leipzig, Johannisallee 30, 04103 Leipzig, Germany
}

Correspondence should be addressed to Hubertus Himmerich; hubertus.himmerich@medizin.uni-leipzig.de

Received 24 June 2013; Revised 2 February 2014; Accepted 7 February 2014; Published 16 March 2014

Academic Editor: Felipe Dal-Pizzol

Copyright (C) 2014 Hubertus Himmerich et al. This is an open access article distributed under the Creative Commons Attribution License, which permits unrestricted use, distribution, and reproduction in any medium, provided the original work is properly cited.

\begin{abstract}
Increased cytokine production possibly due to oxidative stress has repeatedly been shown to play a pivotal role in the pathophysiology of epilepsy and bipolar disorder. Recent in vitro and animal studies of valproic acid (VPA) report antioxidative and anti-inflammatory properties, and suppression of interleukin (IL)- 6 and tumor necrosis factor (TNF)- $\alpha$. We tested the effect of drugs with antiepileptic or mood stabilizer properties, namely, primidone (PRM), carbamazepine (CBZ), levetiracetam (LEV), lamotrigine (LTG), VPA, oxcarbazepine (OXC), topiramate (TPM), phenobarbital (PB), and lithium on the production of the following cytokines in vitro: interleukin (IL)-1 $\beta$, IL-2, IL-4, IL-6, IL-17, IL-22, and TNF- $\alpha$. We performed a whole blood assay with stimulated blood of 14 healthy female subjects. Anti-human CD3 monoclonal antibody OKT3, combined with 5C3 antibody against CD40, was used as stimulant. We found a significant reduction of IL-1 and IL-2 levels with all tested drugs other than lithium in the CD3/5C3-stimulated blood; VPA led to a decrease in IL-1 $\beta$, IL-2, IL-4, IL-6, IL-17, and TNF- $\alpha$ production, which substantiates and adds knowledge to current hypotheses on VPA's anti-inflammatory properties.
\end{abstract}

\section{Introduction}

Immunological processes play a role in the pathophysiology of a variety of brain diseases such as infections, autoimmune, or neurodegenerative diseases and psychiatric disorders [110]. Specifically, changes in the immune system have been implicated in the pathophysiology of bipolar disorder and some types of epilepsies [11-13].

One possible cause of cytokine changes in epilepsy and bipolar disorder is oxidative stress. Oxidative stress is a state of imbalance in the production of reactive oxygen species (ROS) and nitrogen [14], which increases production of proinflammatory cytokines such as interleukin (IL)-1, IL-6, and tumor necrosis factor- $\alpha$ (TNF- $\alpha$ ) [15-19]. The genetic make-up of the defense system against oxidative stress, for example, genetic variants of the superoxide dismutase gene, also influences cytokine production [20]. Increasing evidence indicates that oxidative stress can play a role in a wide range of neurological and psychiatric disorders, including epilepsy and affective disorders [21-24].

Proinflammatory cytokines have also been shown to lead to oxidative stress by producing reactive oxygen species $[25$, 26]. Besides oxidative stress, cytokines can be altered due to genetic predisposition, psychosocial stress, sleep disturbance, inadequate nutrition, and changes in cellular components of the immune system [27-30].

For epilepsy and bipolar disorder, overlapping results regarding the cytokine system have been reported, namely, 
alterations of IL-1 $\beta$, IL-2, IL-4, IL-6, and TNF- $\alpha[12,31-34]$. Of these, data regarding IL- 2 and IL- 4 is limited and the few studies do not show consistent results. Also, the involvement of IL-17 and IL-22 in the pathogenesis of epilepsy or bipolar disorder has not been investigated, although they play important roles in inflammatory immune responses [35-38]. Bipolar disorder and epilepsy not only share immunological abnormalities; some antiepileptic drugs are also used to treat bipolar disorder. Valproic acid (VPA), carbamazepine (CBZ), and lamotrigine (LTG) are antiepileptic drugs (AEDs) which are evidence-based treatments for bipolar disorder. There are also indications of therapeutic potential for the AEDs oxcarbazepine (OXC), topiramate (TPM), and levetiracetam (LEV) in bipolar disorder [39].

In vitro and in vivo experiments show that AEDs as well as mood stabilizers such as VPA and lithium can affect cytokine levels. In patients with epilepsy, CBZ, VPA and phenytoin were reported to lead to elevated levels of IL-1 $\beta$, IL-2, IL-5, IL-6, and TNF- $\alpha[40,41]$. In vitro, however, CBZ, VPA, and phenobarbital $(\mathrm{PB})$ were reported to inhibit the production of IL-2, IL-4, IL-6, and TNF- $\alpha$ [40-42]. In patients with affective disorders, $\mathrm{CBZ}$ and lithium led to increased plasma concentrations of TNF- $\alpha$ and its soluble receptors sTNF$\mathrm{R}$ p55 and p75 [43]. The discrepancy of results of in vitro versus in vivo experiments enjoins us to interpret the results of in vitro experiments with caution. Nevertheless, to better understand mechanisms of action and of side effects, it is important to know effects of psychopharmacological agents on different tissues such as blood, liver, or brain tissue.

A relevant line of research in this context is that, in depression and bipolar disorder, the stimulated in vitro production of cytokines has been shown to differ in patients versus controls and to change during successful therapy [4446]. In recent research, we systematically measured levels of IL-1 $\beta$, IL-2, IL-4, IL-6, IL-17, IL-22, and TNF- $\alpha$ in toxic shock syndrome toxin-1 (TSST-1-) stimulated blood supplemented with PRM, CBZ, LEV, LTG, VPA, OXC, TPM, PB, or lithium in a whole blood assay [47]. In this study, we found that IL- $1 \beta$ production was significantly decreased by PRM, CBZ, LEV, LTG, OXC, PB, and lithium. IL-2 significantly decreased by PRM, CBZ, LEV, LTG, VPA, OXC, TPM, and PB. IL22 significantly increased by PRM, CBZ, LEV, OXC, TPM, and lithium and decreased by VPA. TNF- $\alpha$ production significantly decreased under all applied drugs [47]. The immunological stimulant TSST-1 used in this study leads to nonspecific binding of major histocompatibility complex class II (MHC II) with T cell receptors, resulting in polyclonal $\mathrm{T}$ cell activation, stimulation of mononuclear cells, and increased cytokine production $[48,49]$.

In the present study, we aimed to delineate the influence of these drugs on cytokine production by $\mathrm{T}$ and $\mathrm{B}$ cells. Therefore, we used specific stimulators, known to induce cytokine production in $\mathrm{T}$ and $\mathrm{B}$ cells. Murine anti-human CD3 monoclonal antibody OKT3 (muromonab-CD3) binds to the $\mathrm{T}$ cell receptor $\mathrm{CD} 3$ complex and is an established $\mathrm{T}$ cell activator [50]. 5C3 monoclonal antibody which reacts with human CD40 is reported to activate B cells in in vitro functional assays [51]. CD40 is a costimulatory protein found on antigen presenting cells and is required for their activation
$[52,53]$. It is known that activation of CD40 stimulates ROS production by an NADPH oxidase. CD40 receptor stimulation also increases phosphoinositide 3-kinase (PI3K) activity. PI3K, in turn, activates GTPase Racl and increases ROS generation such as $\mathrm{H}_{2} \mathrm{O}_{2}$ and $\mathrm{O}_{2}{ }^{--}$[54] which might contribute to cytokine activation. Additionally, several other mechanisms have been proposed by which CD40 leads to cytokine production, such as protein kinase $\mathrm{B}$ (Akt) and nuclear factor (NF)-kappa B (NF- $\kappa \mathrm{B})$ signaling pathways [55].

\section{Methods and Material}

Subjects. 14 healthy female subjects between 22 and 47 years of age (mean: $29+6.4(\mathrm{SD})$ years). Exclusion criteria were used of illegal drugs or regular alcohol consumption, presence of any immunological, infectious or endocrinological disorder, and a history of psychiatric disorder from an interview by a psychiatrist using the Structured Clinical Interview for DSMIV (SKID-I; German) [56].

Experimental Procedure. The whole blood assay was performed as described previously [57-59]. Blood was taken from all subjects once with a heparin-monovette (Sarstedt, Nürtingen, Germany) and cultured in a whole blood assay within 1-2 h after blood collection. Cell concentration was adjusted at 3-4 × 109 cells/L using RPMI 1640 medium (Biochrom, Berlin, Germany). Subsequently, $100 \mu \mathrm{L}$ of this blood plus RPMI solution was introduced into a tube and mixed with $100 \mu \mathrm{L}$ pure psychopharmacological substance plus RPMI, resulting in a final cell concentration of $1.5-2 \times$ 109 cells/L.

The final concentration of each AED in this mixture was chosen as to the upper reference value of the therapeutic range of the local clinical-chemical laboratory [60]. The concentration of lithium was chosen in accordance with the AGNP-TDM expert group consensus guidelines: therapeutic drug monitoring in psychiatry [61]. We used the following concentrations: PRM: $12 \mu \mathrm{g} / \mathrm{mL}, \mathrm{CBZ}: 10 \mu \mathrm{g} / \mathrm{mL}$, LEV: $90 \mu \mathrm{g} / \mathrm{mL}$, LTG: $12 \mu \mathrm{g} / \mathrm{mL}, \mathrm{VPA}: 100 \mu \mathrm{g} / \mathrm{mL}$, OXC: $30 \mu \mathrm{g} / \mathrm{mL}$, TPM: $25 \mu \mathrm{g} / \mathrm{mL}, \mathrm{PB}: 40 \mu \mathrm{g} / \mathrm{mL}$, and lithium: $1.2 \mathrm{mmol} / \mathrm{L}$. We will subsequently refer to these concentrations as "1-fold." We additionally tested 2-fold these concentrations, that is, $24 \mu \mathrm{g} / \mathrm{mL}, \mathrm{CBZ}: 20 \mu \mathrm{g} / \mathrm{mL}, \mathrm{LEV}: 180 \mu \mathrm{g} / \mathrm{mL}$, LTG $24 \mu \mathrm{g} / \mathrm{mL}$, VPA: $200 \mu \mathrm{g} / \mathrm{mL}$, OXC: $60 \mu \mathrm{g} / \mathrm{mL}$, TPM: $50 \mu \mathrm{g} / \mathrm{mL}, \mathrm{PB}$ : $80 \mu \mathrm{g} / \mathrm{mL}$, and lithium: $2.4 \mathrm{mmol} / \mathrm{L}$.

The control condition was a tube likewise filled with blood and medium, without any psychopharmacological substance. According to the design of this experiment, we prepared 20 samples, one per tube, from the blood of each participant: one tube as unstimulated control condition, one as stimulated control condition, and 18 tubes under stimulated conditions with one of the nine drugs in 2 different concentrations (1-fold and 2-fold concentration). For induction of all cytokines, we used $100 \mathrm{ng} / \mathrm{mL}$ OKT3 plus $100 \mathrm{ng} / \mathrm{mL} 5 \mathrm{C} 3$ (OKT3/5C3).

As we investigated the blood of 14 donors, we had 14 times 20 equals 280 samples in total. Pure substances of the drugs 
were obtained from Sigma-Aldrich Laborchemikalien GmbH (Seelze, Germany). All tubes were covered and samples incubated in an atmosphere of $5 \% \mathrm{CO} 2$ and $37^{\circ} \mathrm{C}$ for $48 \mathrm{~h}$. Cell-free supernatants were harvested after incubation and stored at minus $70^{\circ} \mathrm{C}$.

For quantification of cytokines IL-1 $\beta$, IL-2, IL-4, IL6 , IL-17, and TNF- $\alpha$, we used bead array flow cytometry (FACSArray Bioanalyzer, BD Biosciences, Franklin Lakes, NJ, USA). IL-22 was determined using a human IL-22 DuoSet Elisa (R\&D Systems Europe, Abingdon, UK).

Statistical Analysis. Because of the nonnormal distribution and small number of data points, all comparisons between cytokine concentrations were undertaken with nonparametric paired Wilcoxon tests. Due to the exploratory nature of this study, an uncorrected $P$ value below 0.05 was considered significant.

\section{Results}

General Findings. Stimulation significantly increased the concentration of all cytokines (IL-1 $\beta$, IL-2, IL-4, IL-6, IL-17, IL-22, and TNF- $\alpha$ ); see Table 1 for descriptive statistics of cytokine levels and for the comparison between unstimulated and OKT3/5C3-stimulated blood. Without stimulation, cytokines were not measurable in most samples. For example, IL-22 levels were below the detection level in 12 of 14 unstimulated samples $(N=2$; see Table 1$)$, whereas stimulation with OKT3/5C 3 rendered IL-22 detectable in most cases. However, the number of cases $N=2$ of measurable IL-22 levels in the unstimulated samples was too small to obtain a significant difference in the Wilcoxon test when comparing stimulated and unstimulated IL-22 levels.

Specific Findings. Details of median and quartiles of measured cytokines are shown in Table 1. Means \pm standard error of the mean (SEM) of IL-1 $\beta$, IL-2, IL-6; and TNF- $\alpha$ for assays with the 1-fold drug concentration is shown in Figures 1, 2, 3, and 4.

We focus in this section mainly on those significant findings seen at both applied concentrations, assuming these findings to have the highest consistency. IL- $1 \beta$ production was significantly lowered by most AEDs, namely, PRM, CBZ, LEV, LTG, OXC, VPA, and PB at both applied concentrations, but not lithium in any concentration. IL-2 production decreased significantly under PRM, CBZ, LEV, LTG, VPA, OXC, and TPM in both concentrations, whereas IL-2 increased significantly under lithium at 2-fold concentration. VPA and LTG reduced IL-4 levels consistently across the two applied concentrations; IL-6 levels decreased significantly under PRM, CBZ, LEV, LTG, VPA, OXC, and TPM at both concentrations and $\mathrm{PB}$ at 1 -fold concentration, and not under lithium. IL-17 decreased significantly under LTG and VPA at both concentrations and increased under lithium. IL-22 levels were significantly increased by lithium at 2 fold concentration. Finally, TNF- $\alpha$ production decreased significantly only under VPA at both applied concentrations.

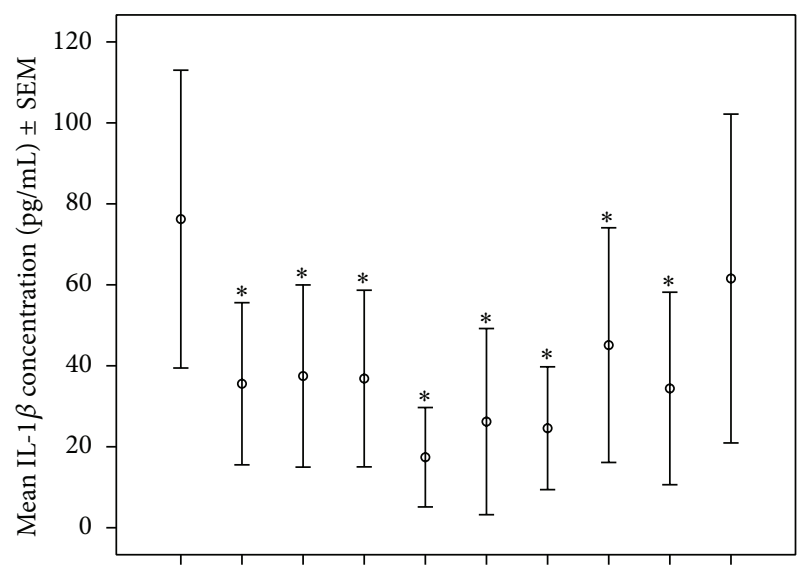

w/o PRM CBZ LEV LTG VPA OXC TPM PB Lithium

FIgure 1: Mean \pm SEM of IL-1 $\beta$ concentrations in OKT3/5C3stimulated whole blood assay without or with mood stabilizers or AEDs at 1-fold concentration (PRM: $12 \mu \mathrm{g} / \mathrm{mL}, \mathrm{CBZ}: 10 \mu \mathrm{g} / \mathrm{mL}, \mathrm{LEV}$ : $90 \mu \mathrm{g} / \mathrm{mL}$, LTG: $12 \mu \mathrm{g} / \mathrm{mL}$, VPA: $100 \mu \mathrm{g} / \mathrm{mL}$, OXC: $30 \mu \mathrm{g} / \mathrm{mL}$, TPM: $25 \mu \mathrm{g} / \mathrm{mL}, \mathrm{PB}: 40 \mu \mathrm{g} / \mathrm{mL}$, and lithium: $1.2 \mathrm{mmol} / \mathrm{L}) .{ }^{*}$ Significant difference between cytokine values in $\mathrm{OKT} 3 / 5 \mathrm{C} 3$-stimulated blood and $\mathrm{OKT} 3 / 5 \mathrm{C} 3$-stimulated blood with supplementation of the listed drugs.

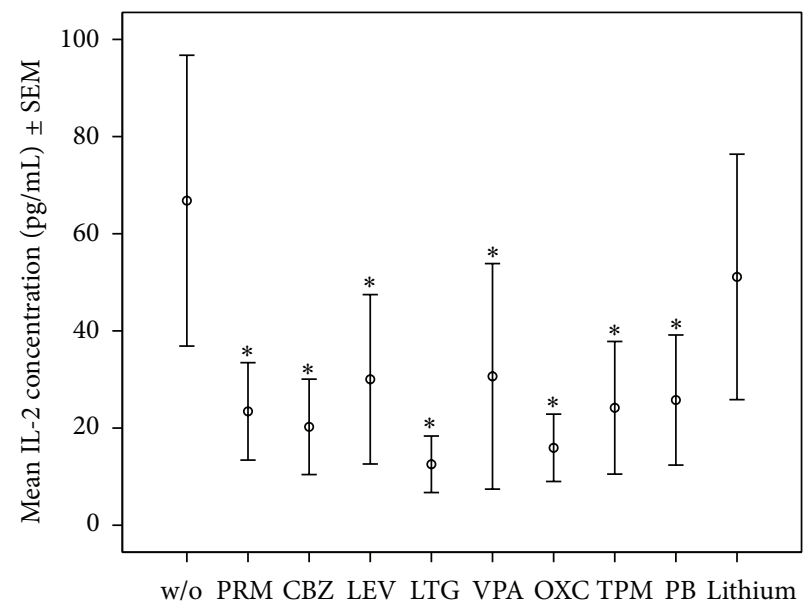

FIGURE 2: Mean \pm SEM of IL-2 concentrations in OKT3/5C3stimulated whole blood assay without or with mood stabilizers or AEDs at 1-fold concentration. ${ }^{*}$ Significant difference between cytokine values in OKT3/5C3-stimulated blood and OKT3/5C3stimulated blood with supplementation of the listed drugs.

Some immunomodulatory effects of the tested drugs were dose dependent (see Table 1). However, the differences in cytokine production between the two tested drug concentrations were not systematically significant.

\section{Discussion}

In this in vitro paradigm, blood cells were stimulated by OKT3 and 5C3 antibodies to enhance the modulatory effects of AEDs and lithium on cytokine production. The main findings were that the significant reduction of IL-1 and IL-2 


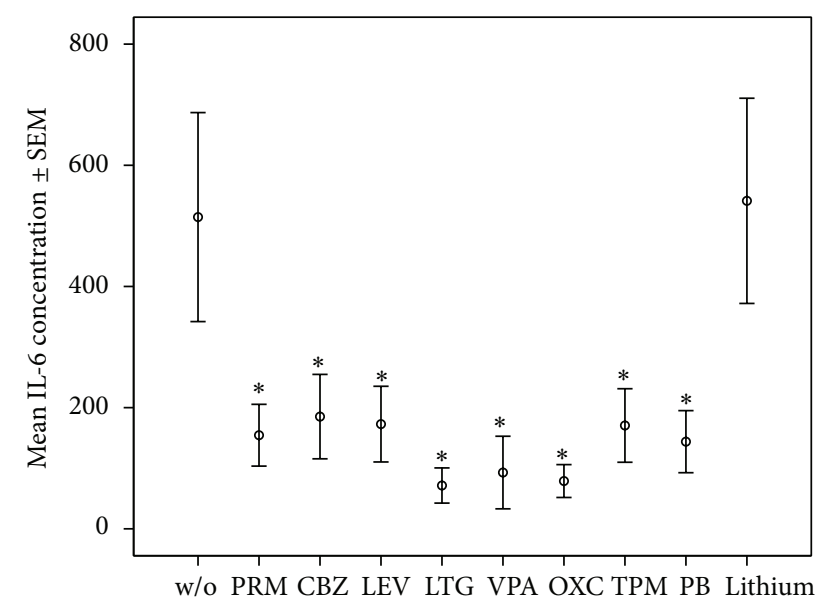

FIGURE 3: Mean \pm SEM of IL-6 concentrations in OKT3/5C3stimulated whole blood assay without or with mood stabilizers or AEDs at 1-fold concentration. ${ }^{*}$ Significant difference between cytokine values in OKT3/5C3-stimulated blood and OKT3/5C3stimulated blood with supplementation of the listed drugs.

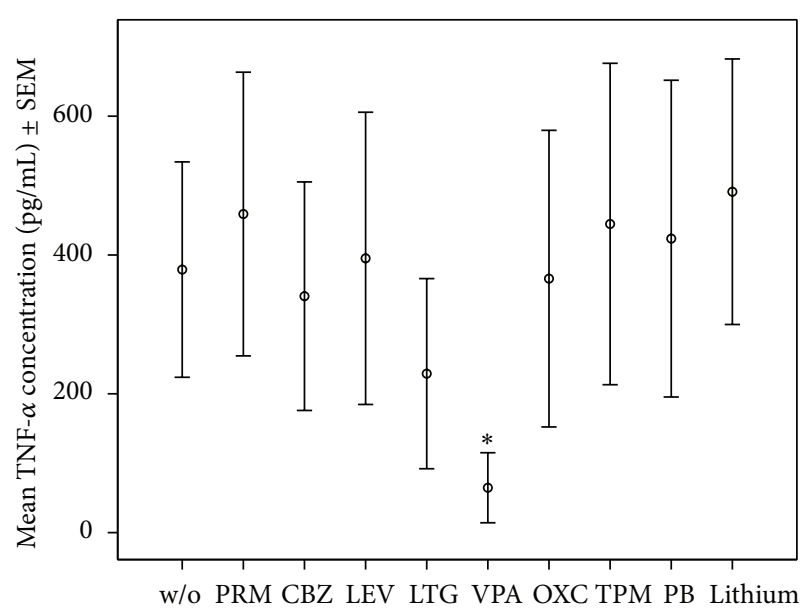

FIgURE 4: Mean and \pm SEM of TNF- $\alpha$ concentrations in OKT3/5C3-stimulated whole blood assay without or with mood stabilizers or AEDs at 1-fold concentration. * Significant difference between cytokine values in $\mathrm{OKT} 3 / 5 \mathrm{C} 3$-stimulated blood and OKT3/5C3-stimulated blood with supplementation of the listed drugs.

levels was made by most of the tested drugs but not lithium and that VPA leads to a decrease in IL-1 $\beta$, IL-2, IL-4, IL-6, IL-17, and TNF- $\alpha$ production. No other antiepileptic drug or mood stabilizer led to such a general decrease in cytokine production.

In bipolar disorders as well as in epilepsy and febrile seizures, IL-1 $\beta$ levels have been reported to be increased. IL$1 \beta$ has been hypothesized to contribute to the pathogenesis of epilepsy, and anti-IL-1 $\beta$ medication has been hypothesized to have therapeutic potential as AED $[13,32,62,63]$. Therefore, the decrease in IL- $1 \beta$ production may be a complementary mechanism by which AEDs exert their antiepileptic action.
Our findings that all AEDs reduced IL-2 production in a whole blood assay are in line with previous studies which showed that CBZ [41], PB [42] of PRM, LEV, LTG, VPA, OXC, and TPM [47] inhibit stimulated IL-2 production in vitro. This finding may also be relevant for the action of antiepileptic drugs in the brain, because IL-2 is epileptogenic, producing EEG alterations after intracerebroventricular administration such as single spikes, polyspikes, or spike waves $[64,65]$.

One possible explanation how AEDs and mood stabilizers influence immune cells could be the modulation of ion channels. Immune cells express these channels, and they are important for their function. Specific lymphocyte functions such as lymphocyte development, selection, differentiation, invasive capacity, cytotoxicity, $\mathrm{T}$ cell receptor activation, and cytokine production all depend on ion-conducting channels for sodium, potassium, calcium, and chloride [66-70].

Not only in lymphocytes but also in macrophages sodium channels serve important functions. In macrophages they are necessary for organelle polarization and are therefore expressed in endosomes and phagolysosomes to regulate phagocytosis [71]. Dysfunction of these channels in macrophages is hypothesized to contribute to a broad spectrum of health problems ranging from an attenuated defense against mycobacteria [72] to the development of multiple sclerosis lesions [71].

As mentioned above, some AEDs (VPA, PB, and TPM) act on the GABA system. In recent years, GABA has been shown to act as an immunomodulatory molecule and appears to modulate a wide variety of functional properties of the cells including cell proliferation, cytokine secretion, phagocytic activity, and chemotaxis [73-76]. GABA receptors seem to be important, for example, for $\mathrm{T}$ lymphocytes, as different subtypes of GABA receptors are expressed in human, mouse, and rat $\mathrm{T}$ lymphocytes [77]. One has to bear in mind that the GABA-A receptor is an ionotropic receptor which selectively conducts chloride ions through its pore, resulting in hyperpolarization of a cell.

In the present study, VPA led to decreased production of various cytokines, namely, IL- $1 \beta$, IL-2, IL-4, IL-6, IL-17, and TNF- $\alpha$. It has already been shown that VPA suppresses lipopolysaccharide-induced production of TNF- $\alpha$ and IL- 6 in vitro $[78,79]$. It is also reported that VPA inhibits the ischemia-induced nuclear translocation of nuclear factor- $\kappa \mathrm{B}$ $(\mathrm{NF} \kappa \mathrm{B})$ activation and matrix metalloproteinase 9 production in vivo and has protective effects against various types of ischemia and reperfusion injury as well as inflammatory diseases [80-84].

In a very recent and, in our opinion, methodologically rigorous study regarding the influence of VPA on ischemic, inflammatory, and oxidative damage in rats, Suda et al. [85] explored the effect of VPA on experimental ischemic stroke and on myeloperoxidase (MPO), microglia (Ibal), 4-hydroxy-2-nonenal (4-HNE), and 8-hydroxydeoxyguanosine (8-OHdG). MPO produces hypochlorous acid ( $\mathrm{HOCl}$ ) from $\mathrm{H}_{2} \mathrm{O}_{2}$ and chloride anion $\left(\mathrm{Cl}^{-}\right)$. 4- $\mathrm{HNE}$ is a product and mediator of oxidative stress [86]. 8-OHdG is a marker of oxidative DNA damage which has been shown 
TABLE 1: Median, first (1. Qu), and third (3. Qu) quartile of cytokine levels in unstimulated blood, OKT3/5C3-stimulated blood, and OKT3/5C3-stimulated blood with mood stabilizers and AEDs at 1-fold (PRM: $12 \mu \mathrm{g} / \mathrm{mL}, \mathrm{CBZ}: 10 \mu \mathrm{g} / \mathrm{mL}, \mathrm{LEV}: 90 \mu \mathrm{g} / \mathrm{mL}, \mathrm{LTG}: 12 \mu \mathrm{g} / \mathrm{mL}$, VPA: $100 \mu \mathrm{g} / \mathrm{mL}$, OXC: $30 \mu \mathrm{g} / \mathrm{mL}$, TPM: $25 \mu \mathrm{g} / \mathrm{mL}, \mathrm{PB}: 40 \mu \mathrm{g} / \mathrm{mL}$, and lithium: $1.2 \mathrm{mmol} / \mathrm{L}$ ) and 2-fold concentration.

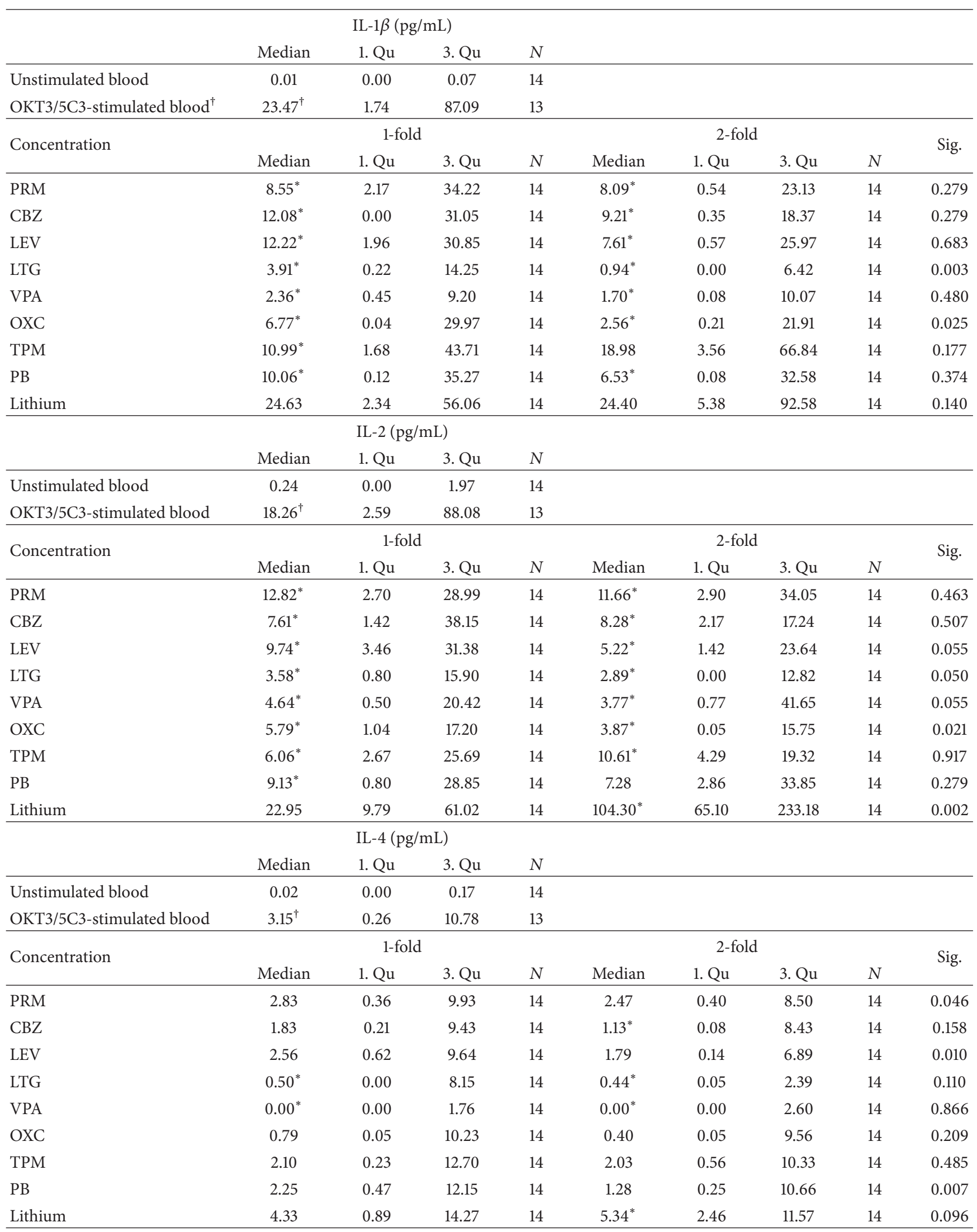


TABle 1: Continued.

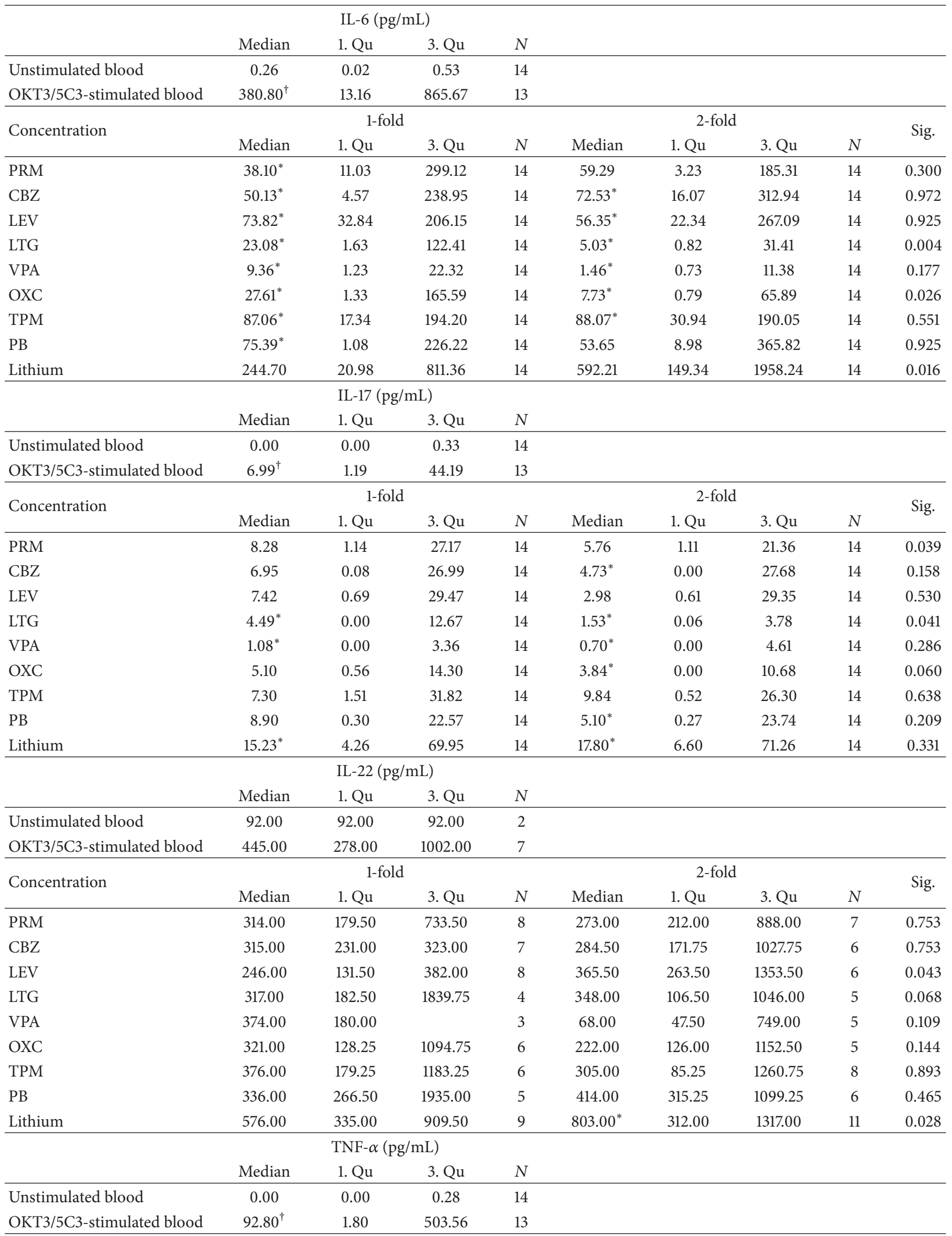


TABLE 1: Continued.

\begin{tabular}{|c|c|c|c|c|c|c|c|c|c|}
\hline \multirow{2}{*}{ Concentration } & \multicolumn{4}{|c|}{ 1-fold } & \multicolumn{4}{|c|}{2 -fold } & \multirow{2}{*}{ Sig. } \\
\hline & Median & 1. $\mathrm{Qu}$ & 3. $\mathrm{Qu}$ & $N$ & Median & 1. $\mathrm{Qu}$ & 3. $\mathrm{Qu}$ & $N$ & \\
\hline PRM & 206.87 & 11.68 & 540.99 & 14 & 167.15 & 17.03 & 530.13 & 14 & 0.470 \\
\hline $\mathrm{CBZ}$ & 149.75 & 12.89 & 388.72 & 14 & 93.72 & 7.44 & 307.18 & 14 & 0.701 \\
\hline LEV & 121.55 & 21.20 & 379.89 & 14 & 81.81 & 9.87 & 452.42 & 14 & 0.917 \\
\hline LTG & 48.31 & 2.01 & 203.86 & 14 & 14.90 & 0.00 & 76.64 & 14 & 0.272 \\
\hline VPA & $7.28^{*}$ & 0.72 & 31.57 & 14 & $8.37^{*}$ & 0.60 & 64.47 & 14 & 0.583 \\
\hline OXC & 88.64 & 0.32 & 352.93 & 14 & 83.95 & 1.21 & 442.08 & 14 & 0.861 \\
\hline TPM & 133.71 & 22.48 & 542.04 & 14 & 240.79 & 15.32 & 887.72 & 14 & 0.008 \\
\hline PB & 99.87 & 4.69 & 589.68 & 14 & 100.96 & 4.92 & 385.65 & 14 & 0.754 \\
\hline Lithium & 326.25 & 43.69 & 912.04 & 14 & $364.50^{*}$ & 85.15 & 1027.79 & 14 & 0.019 \\
\hline
\end{tabular}

$N=$ number of measurable cytokines. ${ }^{\dagger}$ Significant difference between cytokine values in unstimulated and OKT3/5C3-stimulated blood. ${ }^{*}$ Significant difference between cytokine values in OKT3/5C3-stimulated blood and OKT3/5C3-stimulated blood with supplementation of the listed drugs at specified concentrations. Sig.: level of significance of the difference between cytokine values at the 1-fold and cytokine values at the 2 -fold drug concentration.

to be increased, for example, in the urine of patients with depression [87].

Suda et al. found that VPA significantly reduced infarct volume and improved neurological deficit in rats under oxidative stress. Moreover, VPA significantly reduced MPOpositive cells, Ibal-positive cells, 4-HNE-positive cells, and 8OHdG-positive cells compared with vehicle in the ischemic boundary zone. They concluded from their results that VPA has anti-inflammatory as well as antioxidative effects [85]. The inhibition of TNF- $\alpha$ production along with a decrease in MPO release due to VPA has also recently been found in a peritonitis paradigm in mice [88]. These findings of antioxidative and anti-inflammatory properties of VPA are consistent with our in vitro results of a decrease in cytokine production.

This study only included young female subjects and does not permit generalization to male subjects or other age groups. We did not control for the menstrual cycle as a possible confounding factor. However, a systematic bias is unlikely.

In previous studies, we used TSST-1 for stimulation to enhance the modulatory effects of different drugs on cytokine production $[47,59,89]$. TSST-1-as already explained in the introduction-is a staphylococcal-secreted exotoxin which leads to nonspecific binding of major histocompatibility complex class II with $\mathrm{T}$ cell receptors, resulting in $\mathrm{T}$ as well as B cell activation, stimulation of mononuclear cells, and increased cytokine production $[48,49,90]$. Thus, TSST1 is a very reliable but supraphysiological immunological stimulator which may therefore be too strong to simulate blood cells in a clinically relevant manner. Hence, in the present study, we sought to stimulate only lymphocytes using OKT3 combined with 5C3 to influence CD 3 and CD40. This approach has successfully been tested for investigating the effect of antidepressants on cytokine production in vitro [91]. But in further studies one should use either OKT3 or 5C3 to be able to separate $\mathrm{T}$ cell from B cell effects. However, in our previous study using TSST-1 for stimulation, we obtained similar results: IL-1 $\beta$ production was significantly decreased by PRM, CBZ, LEV, LTG, OXC, PB, and lithium, and IL-2 was significantly decreased by PRM, CBZ, LEV, LTG, VPA, OXC, TPM, and PB [47]. Therefore, one can conclude that the results regarding IL- $1 \beta$ and IL-2 show consistency across two different methods.

Another limitation of our study is that the reported effects shown in this in vitro experiment may not be therapeutically relevant for all patients, because most epileptic or bipolar patients do not receive the maximum therapeutic dose. Therefore, it would be advisable for further studies to use lower drug doses too.

Besides IL-1 $\beta$, IL-2, IL-4, IL-6, IL-17, IL-22, and TNF- $\alpha$, several other cytokines such as IL-10, interferon- $\gamma$ (IFN- $\gamma$ ), transforming growth factor (TGF) $-\beta$, erythropoietin (EPO), cytokine receptors such as the TNF- $\alpha$ receptors TNF-R p55 and TNF-R p75, and cytokine receptor antagonists such as the IL-1 receptor antagonist (IL-1ra) have been implicated in the pathophysiology of psychiatric and neurological disorders $[2$, 92, 93]. Therefore, we may have missed effects of AEDs and mood stabilizers on one of these important cytokines.

We did not measure markers of cell death in the reported experiments. Therefore, we can not rule out that cytotoxicity may have contributed to modification of cytokine production due to the tested drugs.

In the statistical analysis we have reported all significant effects at a $P$ level of less than 0.05 . We did not use a correction for multiple tests such as a Bonferroni correction in view of the exploratory nature of the study. But this could reasonably be applied in future research based on a more fine grained power analysis. We did not have access to previous comparable empirical results of experiments using anti-CD3and anti-CD40-stimulated blood. Therefore, we did not have any data for a prospective power analysis while planning this study.

In conclusion, we found significant reductions in IL-1 and IL-2 production by most of the AEDs and mood stabilizers but not lithium. The decrease in cytokine signaling may 
be a complementary mechanism of action of these drugs in the therapy of epilepsy and bipolar disorder. We also found reduction of IL-1 $\beta$, IL-2, IL-4, IL-6, IL-17, and TNF- $\alpha$ release by VPA. These results provide supportive evidence for current hypotheses regarding VPA's anti-inflammatory and antioxidative properties.

\section{Ethical Approval}

The study was approved by the local Ethics Committee of the Medical Faculty of the University of Leipzig (no. 351-1013122010).

\section{Conflict of Interests}

Professor H. Himmerich received speaker honorarium from AstraZeneca, Lilly, and Servier; consulting fees from BristolMyers Squibb; and chemical substances for study support from Lundbeck, AstraZeneca, Novartis, and Wyeth. All other authors reported no biomedical financial interests or potential conflict of interests.

\section{Author's Contribution}

H. Himmerich and S. Bartsch contributed equally to the paper.

\section{Acknowledgment}

The study was supported by the Claussen-Simon Foundation. The mentioned sponsor did not have any influence on study design, collection, analysis, and interpretation of data; writing of the report; or the decision to submit the paper for publication.

\section{References}

[1] A. Nylander and D. A. Hafler, "Multiple sclerosis," Journal of Clinical Investigation, vol. 122, no. 4, pp. 1180-1188, 2012.

[2] H. Himmerich, P. A. Beitinger, S. Fulda et al., "Plasma levels of tumor necrosis factor $\alpha$ and soluble tumor necrosis factor receptors in patients with narcolepsy," Archives of Internal Medicine, vol. 166, no. 16, pp. 1739-1743, 2006.

[3] J. M. Rubio-Perez and J. M. Morillas-Ruiz, "A review: inflammatory process in Alzheimer's disease, role of cytokines," Scientific World Journal, vol. 2012, Article ID 756357, 2012.

[4] K. U. Tufekci, R. Meuwissen, S. Genc, and K. Genc, "Inflammation in Parkinson's disease," Advances in Protein Chemistry and Structural Biology, vol. 88, pp. 69-132, 2012.

[5] M. Maes, M. Berk, L. Goehler et al., "Depression and sickness behavior are Janus-faced responses to shared inflammatory pathways," BMC Medicine, vol. 10, article 66, 2012.

[6] M. Maes, "Depression is an inflammatory disease, but cellmediated immune activation is the key component of depression," Progress in Neuro-Psychopharmacology and Biological Psychiatry, vol. 35, no. 3, pp. 664-675, 2011.

[7] H. Himmerich, S. Fulda, J. Linseisen et al., "Depression, comorbidities and the TNF- $\alpha$ system," European Psychiatry, vol. 23, no. 6, pp. 421-429, 2008.
[8] G. Anderson, M. Berk, S. Dodd et al., "Immuno-inflammatory, oxidative and nitrosative stress, and neuroprogressive pathways in the etiology, course and treatment of schizophrenia," Progress in Neuro-Psychopharmacology and Biological Psychiatry, vol. 42, pp. 1-4, 2013.

[9] H. Himmerich, S. Sorge, K. C. Kirkby, and H. Steinberg, "Schizophrenic disorders: the development of immunological concepts and therapy in psychiatry," Nervenarzt, vol. 83, no. 1, pp. 7-15, 2012.

[10] N. Müller, A. M. Myint, and M. J. Schwarz, "Inflammation in Schizophrenia," Advances in Protein Chemistry and Structural Biology, vol. 88, pp. 49-68, 2012.

[11] L. Stertz, P. V. Magalhães, and F. Kapczinski, "Is bipolar disorder an inflammatory condition? The relevance of microglial activation," Current Opinion in Psychiatry, vol. 26, no. 1, pp. 19-26.

[12] G. Li, S. Bauer, M. Nowak et al., "Cytokines and epilepsy," Seizure, vol. 20, no. 3, pp. 249-256, 2011.

[13] A. Vezzani, S. Balosso, M. Maroso, D. Zardoni, F. Noé, and T. Ravizza, "ICE/caspase 1 inhibitors and IL- $1 \beta$ receptor antagonists as potential therapeutics in epilepsy," Current Opinion in Investigational Drugs, vol. 11, no. 1, pp. 43-50, 2010.

[14] N. Cardenas-Rodriguez, B. Huerta-Gertrudis, L. RiveraEspinosa et al., "Role of oxidative stress in refractory epilepsy: evidence in patients and experimental models," International Journal of Molecular Sciences, vol. 14, no. 1, pp. 1455-1476, 2013.

[15] M. Neri, V. Fineschi, M. di Paolo et al., "Cardiac oxidative stress and inflammatory cytokines response after myocardial infarction," Current Vascular Pharmacology, 2013.

[16] M. Sochocka, E. S. Koutsouraki, K. Gąsiorowski, and J. Leszek, "Vascular oxidative stress and mitochondrial failure in the pathobiology of Alzheimer's disease: new approach to therapy," CNS and Neurological Disorders Drug Targets, vol. 12, no. 6, pp. 870-881, 2013.

[17] E. Corsini, V. Galbiati, D. Nikitovic, and A. M. Tsatsakis, "Role of oxidative stress in chemical allergens induced skin cells activation," Food and Chemical Toxicology, vol. 61, pp. 74-81, 2013.

[18] J. Li, H. Zhang, W. Huang, H. Qian, and Y. Li, “TNF-alpha inhibitors with anti-oxidative stress activity from natural products," Current Topics in Medicinal Chemistry, vol. 12, no. 13, pp. 1408-1421, 2012.

[19] L. Speranza, M. Pesce, A. Patruno et al., "Astaxanthin treatment reduced oxidative induced pro-inflammatory cytokines secretion in U937: SHP-1 as a novel biological target," Marine Drugs, vol. 10, no. 4, pp. 890-899, 2012.

[20] M. A. Montano, I. B. da Cruz, M. M. Duarte et al., "Inflammatory cytokines in vitro production are associated with Ala16Val superoxide dismutase gene," Cytokine, vol. 60, no. 1, pp. 30-33, 2012.

[21] X. Y. Zhang and J. K. Yao, "Oxidative stress and therapeutic implications in psychiatric disorders," Progress in NeuroPsychopharmacology and Biological Psychiatry, vol. 46, pp. 197199, 2013.

[22] S. Rowley and M. Patel, "Mitochondrial involvement and oxidative stress in temporal lobe epilepsy," Free Radical Biology and Medicine, vol. 62, pp. 121-131, 2013.

[23] B. Menon, K. Ramalingam, and R. V. Kumar, "Oxidative stress in patients with epilepsy is independent of antiepileptic drugs," Seizure, vol. 21, no. 10, pp. 780-784.

[24] B. N. Frey, A. C. Andreazza, J. Houenou et al., "Biomarkers in bipolar disorder: a positional paper from the International Society for Bipolar Disorders Biomarkers Task Force," Australian 
and New Zeeland Journal of Psychiatry, vol. 47, no. 4, pp. 321332, 2013.

[25] M. Iborra, I. Moret, F. Rausell et al., "Role of oxidative stress and antioxidant enzymes in Crohn's disease," Biochemical Society Transactions, vol. 39, no. 4, pp. 1102-1106, 2011.

[26] C.-C. Hou, H. Lin, C.-P. Chang, W.-T. Huang, and M.-T. Lin, "Oxidative stress and pyrogenic fever pathogenesis," European Journal of Pharmacology, vol. 667, no. 1-3, pp. 6-12, 2011.

[27] A. M. Fineberg and L. M. Ellman, "Inflammatory cytokines and neurological and neurocognitive alterations in the course of Schizophrenia," Biological Psychiatry, vol. 73, no. 10, pp. 951966, 2013.

[28] H. Himmerich, S. Milenović, S. Fulda et al., "Regulatory T cells increased while IL- $1 \beta$ decreased during antidepressant therapy," Journal of Psychiatric Research, vol. 44, no. 15, pp. 1052-1057, 2010.

[29] Y. Li, B. Xiao, W. Qiu et al., "Altered expression of CD4+CD25+ regulatory T cells and its 5-HTla receptor in patients with major depression disorder," Journal of Affective Disorders, vol. 124, no. 1-2, pp. 68-75, 2010.

[30] H. Himmerich, J. Fischer, K. Bauer, K. C. Kirkby, U. Sack, and U. Krügel, "Stress-induced cytokine changes in rats," European Cytokine Network, vol. 24, no. 2, pp. 97-103, 2011.

[31] S. Hope, I. Dieset, I. Agartz et al., "Affective symptoms are associated with markers of inflammation and immune activation in bipolar disorders but not in Schizophrenia," Journal of Psychiatric Research, vol. 45, no. 12, pp. 1608-1616, 2011.

[32] R. C. Drexhage, E. M. Knijff, R. C. Padmos et al., "The mononuclear phagocyte system and its cytokine inflammatory networks in Schizophrenia and bipolar disorder," Expert Review of Neurotherapeutics, vol. 10, no. 1, pp. 59-76, 2010.

[33] B. H. Nelson, "IL-2, regulatory T cells, and tolerance," Journal of Immunology, vol. 172, no. 7, pp. 3983-3988, 2004.

[34] M. Nowak, S. Bauer, A. Haag et al., "Interictal alterations of cytokines and leukocytes in patients with active epilepsy," Brain, Behavior, and Immunity, vol. 25, no. 3, pp. 423-428, 2011.

[35] N. Y. Hemdan, G. Birkenmeier, G. Wichmann et al., "Interleukin-17-producing $\mathrm{T}$ helper cells in autoimmunity," Autoimmunity Reviews, vol. 9, no. 11, pp. 785-792, 2010.

[36] H. Park, Z. Li, X. O. Yang et al., "A distinct lineage of CD4 T cells regulates tissue inflammation by producing interleukin 17," Nature Immunology, vol. 6, no. 11, pp. 1133-1141, 2005.

[37] G. Murdaca, B. M. Colombo, and F. Puppo, "The role of Th17 lymphocytes in the Autoimmune and Chronic inflammatory diseases," Internal and Emergency Medicine, vol. 6, no. 6, pp. 487-495, 2011.

[38] H. F. Pan, X. P. Li, S. G. Zheng, and D. Q. Ye, "Emerging role of interleukin-22 in autoimmune diseases," Cytokine and Growth Factor Reviews, vol. 24, no. 1, pp. 51-57, 2013.

[39] H. Grunze, E. Vieta, G. M. Goodwin et al., "The World Federation of Societies of Biological Psychiatry (WFSBP) Guidelines for the Biological Treatment of Bipolar Disorders: update 2012 on the long-term treatment of bipolar disorder," World Journal of Biological Psychiatry, vol. 14, no. 3, pp. 154-219.

[40] D. Andrzejczak, "Epilepsy and pro-inflammatory cytokines. Immunomodulating properties of antiepileptic drugs," Neurologia i Neurochirurgia Polska, vol. 45, no. 3, pp. 275-285, 2011.

[41] A. Basta-Kaim, B. Budziszewska, and W. Lasoń, "Effects of antiepileptic drugs on immune system," Przegl, Lekarski, vol. 65, no. 11, pp. 799-802, 2008.
[42] K. D. Yang, W.-Y. Liou, C.-S. Lee, M.-L. Chu, and M.-F. Shaio, "Effects of phenobarbital on leukocyte activation: membrane potential, actin polymerization, chemotaxis, respiratory burst, cytokine production, and lymphocyte proliferation," Journal of Leukocyte Biology, vol. 52, no. 2, pp. 151-156, 1992.

[43] H. Himmerich, D. Koethe, A. Schuld, A. Yassouridis, and T. Pollmächer, "Plasma levels of leptin and endogenous immune modulators during treatment with carbamazepine or lithium," Psychopharmacology, vol. 179, no. 2, pp. 447-451, 2005.

[44] D. L. Krause, M. Riedel, N. Müller, E. Weidinger, M. J. Schwarz, and A.-M. Myint, "Effects of antidepressants and cyclooxygenase-2 inhibitor on cytokines and kynurenines in stimulated in vitro blood culture from depressed patients," Inflammopharmacology, vol. 20, no. 3, pp. 169-176, 2012.

[45] E. M. Knijff, B. M. Nadine, R. W. Kupka et al., "An imbalance in the production of IL- $1 \beta$ and IL- 6 by monocytes of bipolar patients: restoration by lithium treatment," Bipolar Disorders, vol. 9, no. 7, pp. 743-753, 2007.

[46] A. Seidel, V. Arolt, M. Hunstiger, L. Rink, A. Behnisch, and H. Kirchner, "Cytokine production and serum proteins in depression," Scandinavian Journal of Immunology, vol. 41, no. 6, pp. 534-538, 1995.

[47] H. Himmerich, S. Bartsch, H. Hamer et al., "Impact of mood stabilizers and antiepileptic drugs on cytokine production invitro," Journal of Psychiatric Research, vol. 47, no. 11, pp. 17511759, 2013.

[48] M. M. Dinges, P. M. Orwin, and P. M. Schlievert, "Exotoxins of Staphylococcus aureus," Clinical Microbiology Reviews, vol. 13, no. 1, pp. 16-34, 2000.

[49] W. W. S. Kum, K. B. Laupland, R. H. See, and A. W. Chow, "Improved purification and biologic activities of staphylococcal toxic shock syndrome toxin 1," Journal of Clinical Microbiology, vol. 31, no. 10, pp. 2654-2660, 1993.

[50] J. R. Adair, D. S. Athwal, M. W. Bodmer et al., "Humanization of the murine anti-human CD3 monoclonal antibody OKT3," Human Antibodies and Hybridomas, vol. 1, no. 2, pp. 41-47, 1994.

[51] J. D. Pound, A. Challa, M. J. Holder et al., "Minimal crosslinking and epitope requirements for CD40-dependent suppression of apoptosis contrast with those for promotion of the cell cycle and homotypic adhesions in human B cells," International Immunology, vol. 11, no. 1, pp. 11-20, 1999.

[52] J. Banchereau, F. Bazan, D. Blanchard et al., "The CD40 antigen and its ligand," Annual Review of Immunology, vol. 12, pp. 881922, 1994.

[53] C. Caux, C. Massacrier, B. Vanbervliet et al., "Activation of human dendritic cells through CD40 cross-linking," Journal of Experimental Medicine, vol. 180, no. 4, pp. 1263-1272, 1994.

[54] M. Xia, G. Li, J. Ma, and W. Ling, "Phosphoinositide 3-kinase mediates CD40 ligand-induced oxidative stress and endothelial dysfunction via Racl and NADPH oxidase 2," Journal of Thrombosis and Haemostasis, vol. 8, no. 2, pp. 397-406, 2010.

[55] E. F. Gillespie, N. Raychaudhuri, K. I. Papageorgiou et al., "Interleukin-6 production in CD40-engaged fibrocytes in thyroid-associated ophthalmopathy: involvement of Akt and NF- $\kappa$ B," Investigative Ophthalmology and Visual Science, vol. 53, no. 12, pp. 7746-7753, 2012.

[56] H. U. Wittchen, M. Zaudig, and T. Fydrich, Strukturiertes Klinisches Interview für DSM-IV, Hogrefe, Göttingen, Germany, 1997.

[57] H. Kirchner, K. C. Kleinicke Ch., and W. Digel, "A wholeblood technique for testing production of human interferon by 
leukocytes," Journal of Immunological Methods, vol. 48, no. 2, pp. 213-219, 1982.

[58] A. Seidel, V. Arolt, M. Hunstiger, L. Rink, A. Behnisch, and H. Kirchner, "Increased CD56+ natural killer cells and related cytokines in major depression," Clinical Immunology and Immunopathology, vol. 78, no. 1, pp. 83-85, 1996.

[59] H. Himmerich, J. Schönherr, S. Fulda, A. J. Sheldrick, K. Bauer, and U. Sack, "Impact of antipsychotics on cytokine production in-vitro," Journal of Psychiatric Research, vol. 45, no. 10, pp. 13581365, 2011.

[60] E. K. St. Louis, "Monitoring antiepileptic drugs: a level-headed approach," Current Neuropharmacology, vol. 7, no. 2, pp. 115-119, 2009.

[61] P. Baumann, C. Hiemke, S. Ulrich et al., "The AGNP-TDM expert group consensus guidelines: therapeutic drug monitoring in psychiatry," Pharmacopsychiatry, vol. 37, no. 6, pp. 243265, 2004.

[62] R. S. Rao, A. Prakash, and B. Medhi, "Role of different cytokines and seizure susceptibility: a new dimension towards epilepsy research," Indian Journal of Experimental Biology, vol. 47, no. 8, pp. 625-634, 2008.

[63] C. M. Dubé, A. L. Brewster, and T. Z. Baram, "Febrile seizures: mechanisms and relationship to epilepsy," Brain and Development, vol. 31, no. 5, pp. 366-371, 2009.

[64] G. de Sarro, D. Rotiroti, M. G. Audino, S. Gratteri, and G. Nisticó, "Effects of interleukin-2 on various models of experimental epilepsy in DBA/2 mice," Neuroimmunomodulation, vol. 1, no. 6, pp. 361-369, 1994.

[65] G. Nisticò and G. de Sarro, "Is interleukin 2 a neuromodulator in the brain?" Trends in Neurosciences, vol. 14, no. 4, pp. 146-150, 1991.

[66] S. Feske, E. Y. Skolnik, and M. Prakriya, "Ion channels and transporters in lymphocyte function and immunity," Nature Reviews Immunology, vol. 12, no. 7, pp. 532-547, 2012.

[67] W. L. Lo, D. L. Donermeyer, and P. M. Allen, "A voltage-gated sodium channel is essential for the positive selection of CD4(+) T cells," Nature Immunology, vol. 13, no. 9, pp. 880-887, 2012.

[68] S. P. Fraser, J. K. J. Diss, L. J. Lloyd et al., "T-lymphocyte invasiveness: control by voltage-gated $\mathrm{Na}+$ channel activity," The FEBS Letters, vol. 569, no. 1-3, pp. 191-194, 2004.

[69] V. Robert, E. Triffaux, M. Savignac, and L. Pelletier, "Singularities of calcium signaling in effector T-lymphocytes," Biochimica et Biophysica Acta, vol. 1833, no. 7, pp. 1595-1602, 2013.

[70] X. Shi, Y. Bi, W. Yang et al., "Ca2+ regulates T-cell receptor activation by modulating the charge property of lipids," Nature, vol. 493, no. 7430, pp. 111-115, 2013.

[71] J. A. Black, J. Newcombe, and S. G. Waxman, "Navl. 5 sodium channels in macrophages in multiple sclerosis lesions," Multiple Sclerosis, vol. 19, no. 5, pp. 532-542, 2013.

[72] L. M. Carrithers, P. Hulseberg, M. Sandor, and M. D. Carrithers, "The human macrophage sodium channel NaV1.5 regulates mycobacteria processing through organelle polarization and localized calcium oscillations," FEMS Immunology and Medical Microbiology, vol. 63, no. 3, pp. 319-327, 2011.

[73] R. Bhat, R. Axtell, A. Mitra et al., "Inhibitory role for GABA in autoimmune inflammation," Proceedings of the National Academy of Sciences of the United States of America, vol. 107, no. 6, pp. 2580-2585, 2010.

[74] H. Bjurstöm, J. Wang, I. Ericsson et al., "GABA, a natural immunomodulator of T lymphocytes," Journal of Neuroimmunology, vol. 205, no. 1-2, pp. 44-50, 2008.
[75] J. Tian, C. Chau, T. G. Hales, and D. L. Kaufman, "GABA(A) receptors mediate inhibition of $\mathrm{T}$ cell responses," Journal of Neuroimmunology, vol. 96, no. 1, pp. 21-28, 1999.

[76] J. Tian, Y. Lu, H. Zhang, C. H. Chau, H. N. Dang, and D. L. Kaufman, " $\gamma$-Aminobutyric acid inhibits $\mathrm{T}$ cell autoimmunity and the development of inflammatory responses in a mouse type 1 diabetes model," Journal of Immunology, vol. 173, no. 8, pp. 5298-5304, 2004.

[77] S. K. Mendu, A. Bhandage, Z. Jin, and B. Birnir, "Different subtypes of GABA-A receptors are expressed in human, mouse and rat T lymphocytes," PLoS ONE, vol. 7, no. 8, Article ID e42959.

[78] T. Ichiyama, K. Okada, J. M. Lipton, T. Matsubara, T. Hayashi, and S. Furukawa, "Sodium valproate inhibits production of TNF- $\alpha$ and IL- 6 and activation of NF- $\kappa$ B," Brain Research, vol. 857, no. 1-2, pp. 246-251, 2000.

[79] G.-S. Peng, G. Li, N.-S. Tzeng et al., "Valproate pretreatment protects dopaminergic neurons from LPS-induced neurotoxicity in rat primary midbrain cultures: role of microglia," Molecular Brain Research, vol. 134, no. 1, pp. 162-169, 2005.

[80] P. Bhavsar, T. Ahmad, and I. M. Adcock, "The role of histone deacetylases in asthma and allergic diseases," Journal of Allergy and Clinical Immunology, vol. 121, no. 3, pp. 580-584, 2008.

[81] F. Blanchard and C. Chipoy, "Histone deacetylase inhibitors: new drugs for the treatment of inflammatory diseases?" Drug Discovery Today, vol. 10, no. 3, pp. 197-204, 2005.

[82] K. Kim, Y. Li, G. Jin et al., "Effect of valproic acid on acute lung injury in a rodent model of intestinal ischemia reperfusion," Resuscitation, vol. 83, no. 2, pp. 243-248, 2012.

[83] Z. Zhang, Z. Y. Zhang, Y. Wu, and H. J. Schluesener, "Valproic acid ameliorates inflammation in experimental autoimmune encephalomyelitis rats," Neuroscience, vol. 221, pp. 140-150, 2012.

[84] Z. Zhang, N. Tong, Y. Gong et al., "Valproate protects the retina from endoplasmic reticulum stress-induced apoptosis after ischemia-reperfusion injury," Neuroscience Letters, vol. 504, no. 2, pp. 88-92, 2011.

[85] S. Suda, K. Katsura, T. Kanamaru, M. Saito, and Y. Katayama, "Valproic acid attenuates ischemia-reperfusion injury in the rat brain through inhibition of oxidative stress and inflammation," European Journal of Pharmacology, vol. 707, no. 1-3, pp. 26-31, 2013.

[86] K. Uchida, "4-Hydroxy-2-nonenal: a product and mediator of oxidative stress," Progress in Lipid Research, vol. 42, no. 4, pp. 318-343, 2003.

[87] M. Maes, I. Mihaylova, M. Kubera, M. Uytterhoeven, N. Vrydags, and E. Bosmans, "Increased 8-hydroxydeoxyguanosine, a marker of oxidative damage to DNA, in major depression and myalgic encephalomyelitis / chronic fatigue syndrome," Neuro-Endocrinology Letters, vol. 30, no. 6, pp. 715-722, 2009.

[88] J. C. Ximenes, D. de Oliveira Gonçalves, R. M. Siqueira et al., "Valproic acid: an anticonvulsant drug with potent antinociceptive and anti-inflammatory properties," Naunyn-Schmiedeberg's Archives of Pharmacology, vol. 386, no. 7, pp. 575-587, 2013.

[89] H. Himmerich, S. Fulda, A. J. Sheldrick, B. Plümäkers, and L. Rink, "IFN-gamma reduction by tricyclic antidepressants," International Journal of Psychiatry in Medicine, vol. 40, no. 4, pp. 413-424, 2010.

[90] J. R. Tumang, J.-L. Zhou, D. Gietl, M. K. Crow, K. B. Elkon, and S. M. Friedman, "T helper cell-dependent, microbial 
superantigen-mediated B cell activation in vivo," Autoimmunity, vol. 24, no. 4, pp. 247-255, 1996.

[91] A. Munzer, U. Sack, R. Mergl et al., "Impact of antidepressants on cytokine production of depressed patients in vitro," Toxins, vol. 5, no. 11, pp. 2227-2240, 2013.

[92] N. Lichtblau, F. M. Schmidt, R. Schumann, K. C. Kirkby, and H. Himmerich, "Cytokines as biomarkers in depressive disorder: current standing and prospects," International Review of Psychiatry, vol. 25, no. 5, pp. 592-603, 2013.

[93] A. Vezzani, E. Aronica, A. Mazarati, and Q. J. Pittman, "Epilepsy and brain inflammation," Experimental Neurology, vol. 244, pp. 11-21, 2013. 


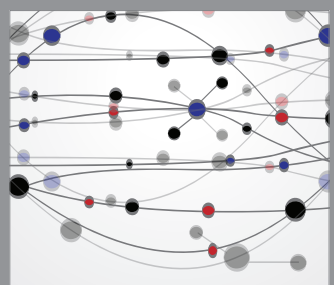

The Scientific World Journal
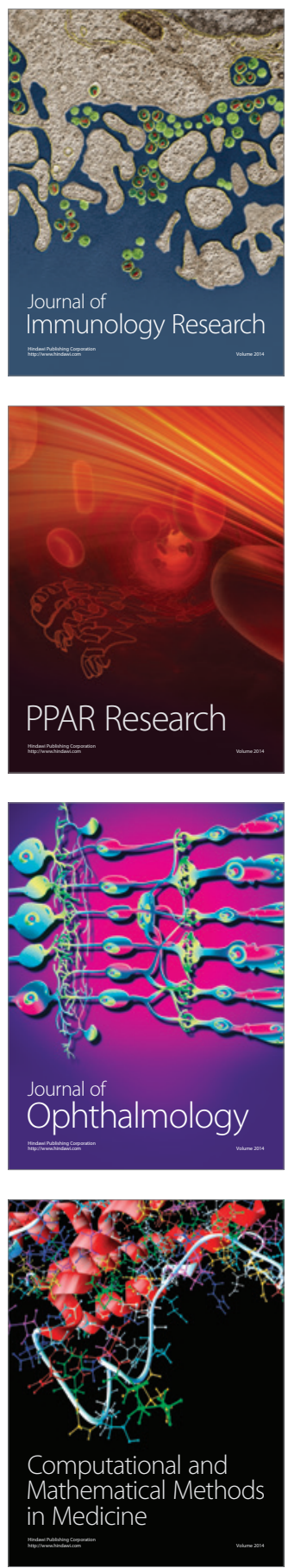

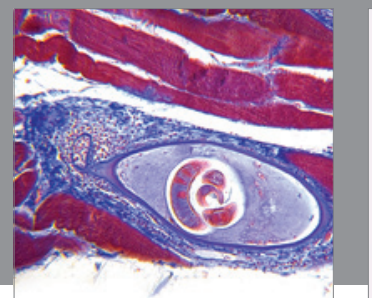

Gastroenterology

Research and Practice
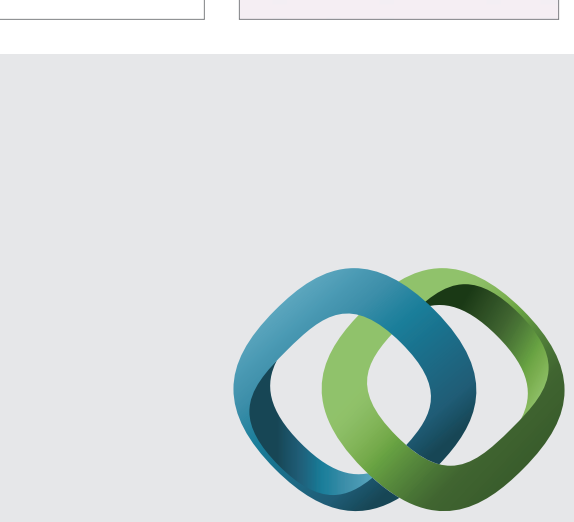

\section{Hindawi}

Submit your manuscripts at

http://www.hindawi.com
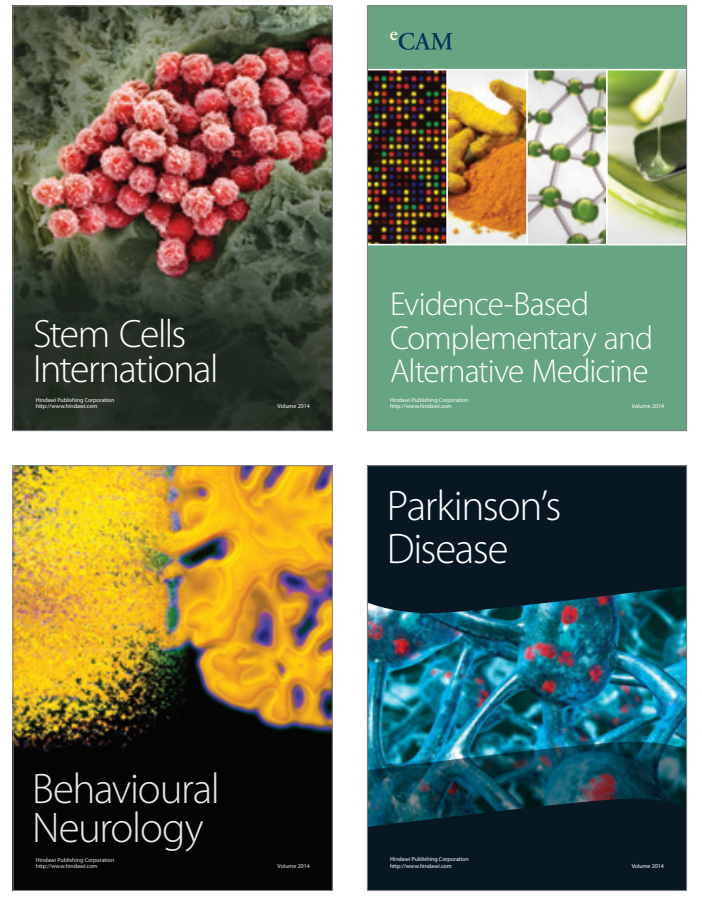
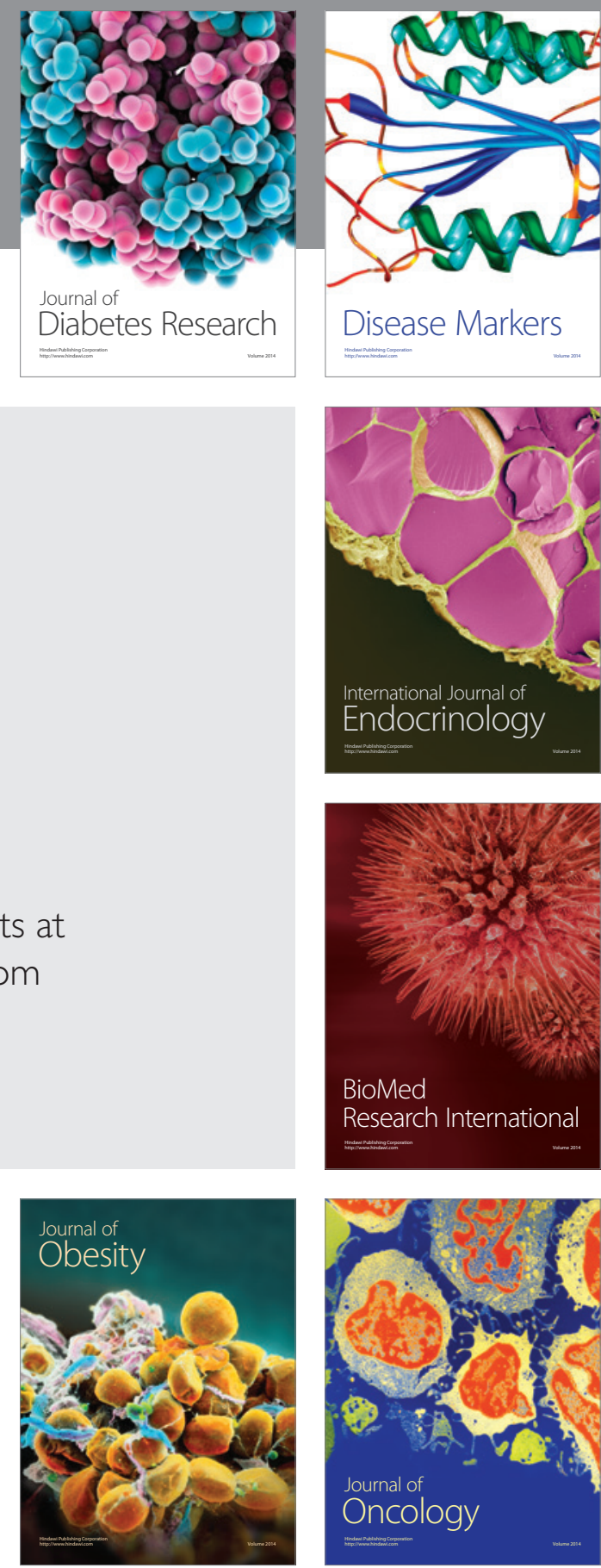

Disease Markers
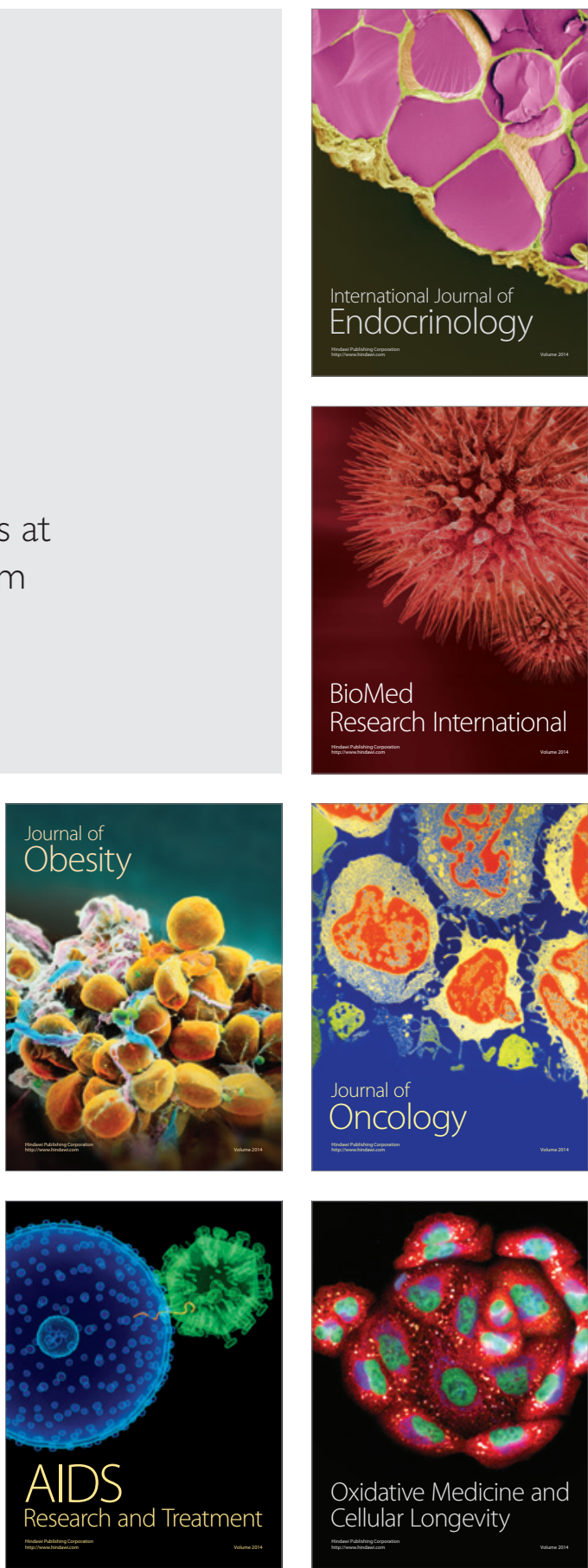